\title{
Kinky choices, dictators and split might: a non-cooperative model for household consumption and labor supply
}

\author{
Jan Boone ${ }^{1}$, Karen van der Wiel ${ }^{2}$, Arthur van Soest ${ }^{3}$ and Frederic Vermeulen ${ }^{4}$.
}

\author{
*Correspondence: \\ frederic.vermeulen@kuleuven.be \\ ${ }^{4}$ IZA, Department of Economics, \\ University of Leuven, Naamsestraat \\ 69, B-3000 Leuven, Belgium \\ Full list of author information is \\ available at the end of the article
}

\begin{abstract}
We model consumption and labor supply behavior of a couple in a non-cooperative setting. Using minimal assumptions, we prove that demand for public goods is characterized by three regimes. It is either determined by the preferences of one of the partners only (Husband Dictatorship or Wife Dictatorship), or by both spouses' preferences, in which case each partner's influence depends on the relative wage rates (Split Might). The model is illustrated empirically using a sample drawn from the Consumer Expenditure Survey (CEX) where expenditures on children's goods are a public good in both spouses' preferences. It turns out that the spending pattern reflects the husband's preferences in about $54 \%$ of the couples in our sample. Still, in about $45 \%$ of the households, the wife acts as a dictator. Somewhat less than $1 \%$ of the couples is characterized by a split might regime.
\end{abstract}

JEL-classification: D11; D12; D13.

Keywords: Consumption; Labor supply; Intra-household allocation; Non-cooperative model; Public goods

\section{Introduction}

Common sense suggests that no two persons, and particularly not one man and one woman, are alike. And although it can be argued that two persons who voluntarily form a household will probably do so on the basis of shared interests and preferences (see, for example, Becker 1973, 1981), no one will maintain that married individuals have identical preferences on all accounts. This means that (economic) decisions taken jointly in a household will be more complicated than those taken by an individual.

One of the important insights from recent applied micro-econometrics is that multiperson households indeed do not behave as single decision makers. Interestingly, early attempts to explicitly account of the fact that multi-person households consist of different individuals with own preferences, like Samuelson (1956) and Becker (1974), actually built upon the idea that households behave as a single decision maker. In Samuelson (1956), the household utility function results by consensus among the household members, while Becker (1974) assumes some benevolent household head who takes into account the preferences of the other household members when allocating time and resources to the household members. The single decision maker assumption, which is fundamental

(O2014 Boone et al.; licensee Springer. This is an Open Access article distributed under the terms of the Creative Commons

Attribution License (http://creativecommons.org/licenses/by/4.0), which permits unrestricted use, distribution, and reproduction in any medium, provided the original work is properly credited. 
to the standard unitary model of household behavior, is associated with the theoretical implication that observed demand or labor supply should satisfy the well-known Slutsky conditions. Slutsky symmetry and negativity, though, are usually rejected when confronted with consumption or labor supply data (see, for example, Fortin and Lacroix 1997; Browning and Chiappori 1998; Cherchye and Vermeulen 2008; and Cherchye et al. 2009). The empirical evidence thus shows that differences in preferences among individuals in multi-person households matter, implying that the nature of the (cooperative or non-cooperative) household decision process cannot be ignored.

A number of alternatives to the unitary model have been put forward. One strand in the literature assumes that household members only choose Pareto efficient allocations. This is either formalized by means of axiomatic bargaining theory (see, for example, Manser and Brown 1980; and McElroy and Horney 1981) or via the so-called collective model (see Chiappori 1988, 1992; and Apps and Rees 1988). Another strand of the literature assumes that household members behave non-cooperatively or semi-cooperatively (see Leuthold 1968; and Ashworth and Ulph 1981, for seminal contributions and Browning 2000; Browning et al. 2010; Lechene and Preston 2011; Cherchye et al. 2011; and d'Aspremont and Dos Santos Ferreira 2014, for recent examples).

One of the main implications of the models that recognize that households do not behave as single decision makers is that intra-household allocations may depend on individual resources of household members rather than on only the household's aggregate means. A leading empirical example in this respect is that children seem to benefit more when the mother (or grandmother) brings relatively more financial resources into the household. This has been consistently shown for both developed and developing countries (e.g. Lundberg, Pollak and Wales 1997, for the U.K., Thomas, Contreras and Frankenberg 1997, for Indonesia, and Duflo 2003, for South Africa). From a policy point of view this dependence on who brings what to the table is very important. It implies that policy makers can alter the intra-household allocation of resources by targeting taxes or transfers to specific household members.

The targeting issue has been investigated in a collective setting (see Blundell et al. 2005; and Cherchye et al. 2012) as well as in a non-cooperative setting. The usual approach in the latter is by considering models that focus on the private provision of public goods (see, among others, Bergstrom et al. 1986; Chen and Woolley 2001; and Lechene and Preston 2011). An important restriction in these existing non-cooperative models is that the individual labor incomes, and thus the household's resources, are assumed exogenous. It is not difficult, however, to come up with arguments in favor of more realistic models that not only explain the intra-household allocation of resources but also how these resources are generated, allowing for the possibility that this is subject to strategic considerations.

A first aim of the current study is to fill this gap in our understanding by focusing on the private provision of public goods while also taking into account labor supply decisions and the implied endogenous individual incomes. We choose this non-cooperative setting not only because of scientific curiosity but also because of its connection with the cooperative setting. As emphasized by Browning et al. (2010), p. 788, cooperative bargaining models often use the non-cooperative outcome as a threat point ${ }^{1}$. Therefore, it is important to understand household behavior in the non-cooperative setting given its implications on the intra-household allocation of resources in the cooperative setting. Moreover, in the case of informational constraints (more specifically, spouses who do not know each 
others' preferences well) or the impossibility to make binding and costlessly enforceable agreements on the transfer of (in our case endogenous) resources, the non-cooperative setting is a useful benchmark.

We will start out with a general model and investigate what can happen to the demand for public goods in this set-up. We define three regimes and show that all Nash equilibria fall in either of these regimes. In the first regime, the husband is dictator (denoted by HD). More specifically, the household's demand for public goods fully reflects the husband's preferences given the household's total resources. The second regime is associated with split might (SM): each spouse's preferences are reflected in the household's spending on public goods. The extent to which this happens depends on the spouses' relative wage rates. In the third regime the wife is the dictator (WD).

Like in Browning et al. (2010), and contrary to Lundberg and Pollak (1993), the regimes are determined 'endogenously' by the spouses' relative wage rates. The main difference between our results and those obtained by Browning et al. (2010) is that we do not have a pure local income pooling phenomenon. This is due to the endogenous individual labor incomes in our model, which rule out exogenous shifts in individual income sources that keep the household's aggregate budget fixed. Still, there is some sort of local income pooling in both dictatorship regimes: total household spending on public goods is as the most powerful spouse would want it to be.

A second contribution of the current study is that the theoretical model for the private provision of public goods with endogenous labor supply will be brought to the data. Contrary to collective models, of which a wide variety of empirical applications are available, empirical evidence for the private provision of public goods remains scarce. This gap will be partly filled in our paper by means of an empirical model that focuses on expenditures on children's goods (such as children's clothing, toys or tuition fees). These child related goods are considered to be public goods inside the household. The empirical model imposes more structure on the general model, leading to testable implications of this model against the standard unitary model. The data for the application are drawn from the Consumer Expenditure Survey (CEX) collected by the Bureau of Labor Statistics of the U.S. Department of Labor. We find that the spouses' preferences with respect to the allocation of the couple's resources differ from each other. Using the estimated preference parameters, we can divide households into dictatorship and split might regimes. We find that in the majority of the couples in our sample (about 54\%), there is a Husband Dictatorship regime, in the sense that the spending pattern on public goods is based upon the husband's preferences. In about $45 \%$ of the couples, there is a Wife Dictatorship. In only a small fraction, there is a Split Might regime. This implies that the regimes are determined endogenously, rather than that they reflect traditional gender roles as in Lundberg and Pollak (1993).

The rest of this paper is organized as follows. In Section 2, we propose a general private provision of public goods model with endogenous labor supply and discuss its implications. Section 3 focuses on the empirical specification and the estimation strategy. The data and estimation results are discussed in Sections 4 and 5. Section 6 concludes.

\section{The model}

We focus on couples of different sex and let $f$ denote the wife and $m$ the husband ${ }^{2}$. Spouses have to decide on their demands for leisure $l^{f}, l^{m} \in[0,1]$ (normalized between 
zero and one), including the option to be out of the labor market $\left(l^{f}=1\right.$ or $\left.l^{m}=1\right)$ and on how the household's aggregate resources are allocated to private goods consumed by the two spouses (denoted by vectors $\mathbf{q}^{f} \in \mathbb{R}_{+}^{n_{f}}, \mathbf{q}^{m} \in \mathbb{R}_{+}^{n_{m}}$ ) and public goods inside the household (denoted by the vector $\mathbf{Q} \in \mathbb{R}_{+}^{n_{p}}$ ). The household's aggregate resources are assumed to be equal to the sum of the individual labor incomes $w^{f}\left(1-l^{f}\right)+w^{m}\left(1-l^{m}\right)$, where $w^{i}$ is individual $i$ 's (potential) wage rate $(i=f, m)$. This implies that, for simplicity, we ignore non-labor income ${ }^{3}$. Prices of private and public goods are denoted by $\mathbf{p}$ and $\mathbf{P}$, respectively (where, with a slight abuse of notation, we use the same notation $\mathbf{p}$ for both private good vectors).

In what follows, we assume that leisure is a private good in the sense that it does not entail intra-household externalities. The wife's and husband's utility functions, representing their own preferences, are therefore given by:

$$
u^{f}\left(l^{f}, \mathbf{q}^{f}, \mathbf{Q}\right)
$$

and

$$
u^{m}\left(l^{m}, \mathbf{q}^{m}, \mathbf{Q}\right) .
$$

The main issue is how household decisions are made. Following, among others, Browning et al. (2010), we assume a non-cooperative setting and assume a Nash equilibrium is attained. A Nash equilibrium is defined as follows:

Definition 1. A Nash equilibrium consists of individual leisure, a vector of individual private consumption and individual contributions to public goods $\left(l^{i *}, \mathbf{q}^{i *}, \mathbf{Q}^{i *}\right), i=f, m$, such that for each $i,\left(l^{i *}, \mathbf{q}^{i *}, \mathbf{Q}^{i *}\right)$ solves for $i \neq j$ :

$$
\begin{aligned}
& \max _{l^{i} \in[0,1], \mathbf{q}^{i}, \mathbf{Q}^{i} \geq 0} u^{i}\left(l^{i}, \mathbf{q}^{i}, \mathbf{Q}^{i}+\mathbf{Q}^{j *}\right) \\
& \text { s.t. } w^{i} l^{i}+\mathbf{p}^{\prime} \mathbf{q}^{i}+\mathbf{P}^{\prime} \mathbf{Q}^{i}=w^{i} .
\end{aligned}
$$

We denote marginal utility with respect to good $x$ by $u_{x}$ and assume that this derivative is well defined. We make the following assumptions on the utility functions (deleting superscripts to ease notation if a condition holds for both partners):

\section{Assumption For arbitrary values of $l, \mathbf{q}, \mathbf{Q}$ we have that}

1. $\lim _{x \downarrow 0} u_{x}(l, \mathbf{q}, \mathbf{Q})=+\infty$ for leisure $(x=l)$, each private good $\left(x=q_{k}\right)$ and each public good $\left(x=Q_{k}\right)$,

2. $\lim _{x \rightarrow+\infty} u_{x}(l, \mathbf{q}, \mathbf{Q})=0$ for each private $\operatorname{good}\left(x=q_{k}\right)$ and each public good $\left(x=Q_{k}\right)$,

3. $u_{l}(1, \mathbf{q}, \mathbf{Q})<+\infty$,

4. $u(l, \mathbf{q}, \mathbf{Q})$ is concave in leisure, each private good and each public good and

5. there exist (at least) two public goods $Q_{k}, Q_{k^{\prime}}$ such that

$$
\frac{u_{Q_{k}}^{f}}{u_{Q_{k^{\prime}}}^{f}}>\frac{u_{Q_{k}}^{m}}{u_{Q_{k^{\prime}}}^{m}} .
$$

The first four assumptions are fairly standard. Assumption 1 says that for each good the marginal utility goes to infinity as the consumed amount of the good goes to zero. The 
second assumption says that for each private and public good the marginal utility goes to zero as the amount of the good goes to infinity. These assumptions are made for ease of exposition. We are interested in corner solutions where one of the partners does not contribute to a public good, but we want to avoid corner solutions in private goods (other than leisure) and total contributions to public goods ${ }^{4}$.

The third assumption implies that $u_{l}$ is finite if the partner does not work at all $(l=1)$. The combination of assumptions 1 and 3 seems to imply that both partners participate in the labor market, as one obtains infinite utility from consuming some private goods and as labor income is the only resource available to pay for these private goods. It is, however, still possible to capture non-participation (of either partner) in the labor market: If all goods are public and there are no private goods other than leisure (as in the empirical application; see Section 3) non-participation arises for a range of positive wage rates ${ }^{5}$.

Assumption 4 imposes concavity, which is sufficient to guarantee that stationary points characterize a global maximum. Assumption 5 is the most interesting one in our context since it implies a conflict within the household: there is a tension between the two partners since they never agree on the overall contributions to the public goods.

Under assumptions 1-5, we can prove the following lemma. The Appendix contains the proof.

Lemma 1. In Nash equilibrium ${ }^{6}$ we have for both partners that

$$
\frac{u_{l}}{u_{q_{k}}}=\frac{w}{p_{k}}
$$

for each private good $q_{k}$.

We will now define three regimes and show below that all Nash equilibria fall in either of these regimes. In the first regime, the husband is the dictator (denoted by HD). More specifically, the household's demand for public goods fully reflects the husband's preferences given the household's aggregate resources. The second regime is associated with split might (SM): each spouse contributes to the public good(s) but not to all of them, and, moreover, has a say on how the household's total resources are allocated. The resulting allocation, however, does not reflect the preferences of either spouse. In the third regime, the wife is the dictator (WD). Like in Browning et al. (2010), and contrary to Lundberg and Pollak (1993), which regime characterizes the equilibrium outcome is determined within the model, and depends on the spouses' relative wage rates. A special case within the SM regime is the Separate Spheres regime of these two studies, where each spouse contributes to strictly different sets of public goods. See Section 3 for a clarifying example.

Formally, we have the following (where we use the convention on inequalities with vectors that $\mathbf{x}<\mathbf{y}$ implies that $x_{k} \leq y_{k}$ for all $k$ with strict inequality for at least one $k$ ).

Definition 2. The three regimes are defined as follows

$$
\begin{aligned}
& \text { HD } u_{\mathbf{Q}^{m}}^{m}=\lambda^{m} \mathbf{P} \text { and } u_{\mathbf{Q}^{f}}^{f}<\lambda^{f} \mathbf{P}, \\
& \mathbf{S M} u_{\mathbf{Q}^{m}}^{m}<\lambda^{m} \mathbf{P} \text { and } u_{\mathbf{Q}^{f}}^{f}<\lambda^{f} \mathbf{P} \text { and } \\
& \text { WD } u_{\mathbf{Q}^{m}}^{m}<\lambda^{m} \mathbf{P} \text { and } u_{\mathbf{Q}^{f}}^{f}=\lambda^{f} \mathbf{P} .
\end{aligned}
$$


where $\lambda^{i}=u_{q_{k}}^{i} / p_{k}$ (from Lemma 1) is the Lagrange multiplier associated with partner $i$ 's budget constraint $(i=f, m)$.

The following proposition demonstrates that the three regimes above are the only ones that can occur in equilibrium. The proof can be found in the Appendix.

Proposition 1. If $w^{m}>0$ and/or $w^{f}>0$, then HD, SM and WD are the only possibilities. That is, each Nash equilibrium (satisfying (2)) is characterized by the equalities in Lemma 1 and the conditions in either HD, SM or WD.

In the example of Browning et al. (2010) the regimes are ordered as HD, (our) SM and WD, and the ordering is a function of the wife's share of household income (which is assumed exogenous in their setting). We present a similar result, with endogenous incomes, for the specific case in the next section. Here we consider what we can say about the ordering in our general set-up. Proposition 2 (partially) characterizes the ordering of the three regimes in terms of relative (potential) wage rates $\rho=w^{f} / w^{m}$. See the Appendix for a proof.

Proposition 2. There exist critical values $\rho_{0}>0$ and $\rho_{1}>\rho_{0}$ such that the household is in regime HD for each $w^{f} / w^{m}<\rho_{0}$ and in regime $W D$ for each $w^{f} / w^{m}>\rho_{1}$.

Our empirical specification in the next section imposes more structure on the utility functions $u^{m}$ and $u^{f}$. This allows us to show that for given $w^{m}>0$ we move through the regimes as $w^{f}$ increases in the order HD, SM and finally WD. With the general set-up in this section we cannot rule out an ordering like HD, SM, HD (again), WD. Still, it is both surprising and insightful that we can prove a result like Proposition 2 given the few assumptions that we have made.

The robust insight is that when one partner (potentially) has a sufficiently higher wage rate compared to that of the other partner, the household allocation to public goods is determined completely by this partner's preferences - given the household's aggregate resources. That is, one always starts with HD (for low $\rho$ and a wife who does not participate to the labor market) and ends up with WD (for high $\rho$ and a working wife).

\section{Empirical specification and estimation strategy}

\subsection{Empirical specification}

We will illustrate the existence of dictatorship and split might regimes by means of a sample of couples with children drawn from the Consumer Expenditure Survey (CEX). This data set not only contains detailed purchases of each household but also information on wages and labor supply of each household member (see the next subsection for more details). Given the limitations of the particular data at hand, we will focus on a special case of the general model described above. The three possible regimes continue to be Husband Dictatorship, Split Might and Wife Dictatorship, as in the general set up described in the previous section. But we make several simplifications. First, it turns out that almost all prime age men in the selected sample work full time. We will therefore assume that men's labor supply is exogenously fixed. Wives, on the contrary, are assumed to be able to choose any number of working hours they want, including non-participation. Wives' 
leisure is the only private good in the model. Second, as is common in budget surveys, expenditures are recorded at the household level. This implies that, for most goods, each spouse's individual consumption of private goods is not observed. We will therefore make the simplifying assumption that all consumption in the household is public. Two public goods will be distinguished: a composite good that relates to expenditures on children's goods (such as clothing, toys and tuition fees) and a composite good relating to other nondurable expenditures.

To obtain a tractable empirical specification, we will assume that spouses have preferences that can be represented by Cobb-Douglas utility functions. The utility functions of husband and wife are specified as follows:

$$
\begin{aligned}
& u^{m}=\beta \ln Q_{1}+(1-\beta) \ln Q_{2} \\
& u^{f}=\omega \ln l^{f}+(1-\omega)\left(\alpha \ln Q_{1}+(1-\alpha) \ln Q_{2}\right),
\end{aligned}
$$

where $Q_{1}$ and $Q_{2}$ are the composite goods related to non-children's and children's goods, respectively, and $l^{f}$ is the wife's leisure. Let us denote the respective prices of the two public goods by $P_{1}$ and $P_{2}$. The spouse-specific preference parameters $\alpha, \beta$ and $\omega$ are assumed to be between zero and one.

We will not make any assumption on the spouses' relative valuation of the public goods, but let the data speak instead. In other words, we will not impose that, say, the wife values the child related public good more than the husband. Therefore, two cases can be distinguished: if $\beta>\alpha$ the husband values the child related public good less than the wife, while the reverse holds if $\beta<\alpha$. (The case $\beta=\alpha$ does not satisfy Assumption 5.)

Let us first focus on the scenario $\beta>\alpha$. As shown below in detail, this model is associated with three regimes, like the general model in Section 2 . The first regime is characterized by dictatorship of the husband, which implies that the household's aggregate resources are entirely allocated according to the husband's preferences. Importantly, this regime is associated with two subregimes: a subregime where the wife does not participate in the labor market and a subregime where the wife participates (but the husband is still the dictator). The second regime is associated with split might. Given the assumption that $\beta>\alpha$, the child related public good is in this case entirely financed by the wife, while the other public good is entirely financed by the husband. This situation corresponds to the Separate Spheres case in Browning et al. (2010). In the third regime, the wife is the dictator: the household's aggregate resources are allocated to the two public goods according to the wife's preferences. In which of the three regimes a couple will be located depends on the wife's and the husband's wage rates and on both spouses' preference parameters. Below we more formally characterize the three regimes:

Husband dictator First, for when the wife's wage $w^{f}$ is rather small (to be made precise below), the husband dictates the entire allocation over $Q_{1}$ and $Q_{2}$ :

$$
\begin{aligned}
& Q_{1}=\frac{\beta y}{P_{1}} \\
& Q_{2}=\frac{(1-\beta) y}{P_{2}},
\end{aligned}
$$

where

$$
y=w^{m}+\left(1-l^{f}\right) w^{f} .
$$


The wife's labor supply decision in this situation is derived as follows:

$$
\max _{l^{f}} \omega \ln l^{f}+(1-\omega)\left(\alpha \ln \left(\frac{\beta}{P_{1}}\right)+(1-\alpha) \ln \left(\frac{(1-\beta)}{P_{2}}\right)+\ln \left(w^{m}+\left(1-l^{f}\right) w^{f}\right)\right) .
$$

The first order condition for $l^{f}$ can be written as

$$
\frac{l^{f} w^{f}}{y}=\frac{\omega}{1-\omega} .
$$

Solving for $l^{f}$, we get

$$
l^{f}=\omega\left(1+\frac{w^{m}}{w^{f}}\right) .
$$

Taking account of the fact that $l^{f} \leq 1$, the wife will not participate (i.e., $l^{f}=1$ ) if

$$
w^{f} \leq w^{m} \frac{\omega}{1-\omega} .
$$

In this case we have from (5):

$$
\begin{aligned}
Q_{1} & =\frac{\beta w^{m}}{P_{1}} \\
Q_{2} & =\frac{(1-\beta) w^{m}}{P_{2}} .
\end{aligned}
$$

Next consider the case where $w^{f} \in\left[w^{m} \frac{\omega}{1-\omega}, w^{m} \frac{1-\beta(1-\omega)}{\beta(1-\omega)}\right]$. The household's aggregate resources are now given by

$$
y=(1-\omega)\left(w^{f}+w^{m}\right) .
$$

In this case, the husband stays the dictator and the demand functions for public goods are

$$
\begin{aligned}
Q_{1} & =\frac{\beta(1-\omega)\left(w^{f}+w^{m}\right)}{P_{1}} \\
Q_{2} & =\frac{(1-\beta)(1-\omega)\left(w^{f}+w^{m}\right)}{P_{2}} .
\end{aligned}
$$

The wife spends her entire income on $Q_{2}$, so that the husband's contribution to $Q_{2}$ is given by

$$
\begin{aligned}
Q_{2}^{m} & =\frac{(1-\beta)(1-\omega)\left(w^{f}+w^{m}\right)-w^{f}\left(1-l^{f}\right)}{P_{2}} \\
& =\frac{w^{m}-\beta(1-\omega)\left(w^{m}+w^{f}\right)}{P_{2}}
\end{aligned}
$$

This phase stops once $Q_{2}^{m}=0$ which happens when $w^{f} \geq w^{m} \frac{1-\beta(1-\omega)}{\beta(1-\omega)}$.

Split might Assume that $w^{f} \in\left[w^{m} \frac{1-\beta(1-\omega)}{\beta(1-\omega)}, w^{m} \frac{1-\alpha(1-\omega)}{\alpha(1-\omega)}\right]$. This is the situation in which $Q_{2}^{m}=0$ and $Q_{1}^{f}=0$. Now we have

$$
\begin{aligned}
& Q_{1}=Q_{1}^{m}=\frac{w^{m}}{P_{1}} \\
& Q_{2}=Q_{2}^{f}=\frac{(1-\omega) w^{f}-\omega w^{m}}{P_{2}} .
\end{aligned}
$$

This will last until

$$
\frac{Q_{2}}{Q_{1}}=\frac{1-\alpha}{\alpha} \frac{P_{1}}{P_{2}}
$$


or, equivalently, until the wife's wage has risen to

$$
w^{f}=w^{m} \frac{1-\alpha(1-\omega)}{\alpha(1-\omega)} .
$$

Wife dictator For $w^{f} \geq w^{m} \frac{1-\alpha(1-\omega)}{\alpha(1-\omega)}$, the allocation of the household's aggregate resources is entirely determined by the wife's preferences:

$$
\begin{aligned}
Q_{1} & =\frac{\alpha(1-\omega)\left(w^{f}+w^{m}\right)}{P_{1}} \\
Q_{2} & =\frac{(1-\alpha)(1-\omega)\left(w^{f}+w^{m}\right)}{P_{2}} .
\end{aligned}
$$

The above characterization of the three regimes applies when $\beta>\alpha$, i.e., when the wife values the child related public good relatively more than the husband. Figure 1 summarizes what happens in this situation as a function of $w^{f}$, for given values of $w^{m}, \alpha, \beta$ and $\omega$.

A similar characterization can be derived for the situation when $\beta \leq \alpha$ (i.e., when the husband values the child related good more than the wife). The complete characterization of the different regimes for both situations are summarized as follows:

Situation 1: $\beta>\alpha$

$$
\begin{aligned}
& l^{f}=\left\{\begin{array}{ccc}
1 & \text { if } w^{f} \leq \frac{\omega}{1-\omega} w^{m} \\
\omega\left(1+\frac{w^{m}}{w^{f}}\right) & \text { if } w^{f}>\frac{\omega}{1-\omega} w^{m}
\end{array}\right. \\
& Q_{1}=\left\{\begin{array}{ccc}
\frac{\beta w^{m}}{P_{1}} & \text { if } & w^{f} \leq \frac{\omega}{1-\omega} w^{m} \\
\frac{\beta(1-\omega)\left(w^{f}+w^{m}\right)}{P_{1}} & \text { if } & w^{f} \in\left[w^{m} \frac{\omega}{1-\omega}, w^{m} \frac{1-\beta(1-\omega)}{\beta(1-\omega)}\right] \\
\frac{w^{m}}{P_{1}} & \text { if } w^{f} \in\left[w^{m} \frac{1-\beta(1-\omega)}{\beta(1-\omega)}, w^{m} \frac{1-\alpha(1-\omega)}{\alpha(1-\omega)}\right] \\
\frac{\alpha(1-\omega)\left(w^{f}+w^{m}\right)}{P_{1}} & \text { if } & w^{f}>w^{m} \frac{1-\alpha(1-\omega)}{\alpha(1-\omega)}
\end{array}\right.
\end{aligned}
$$

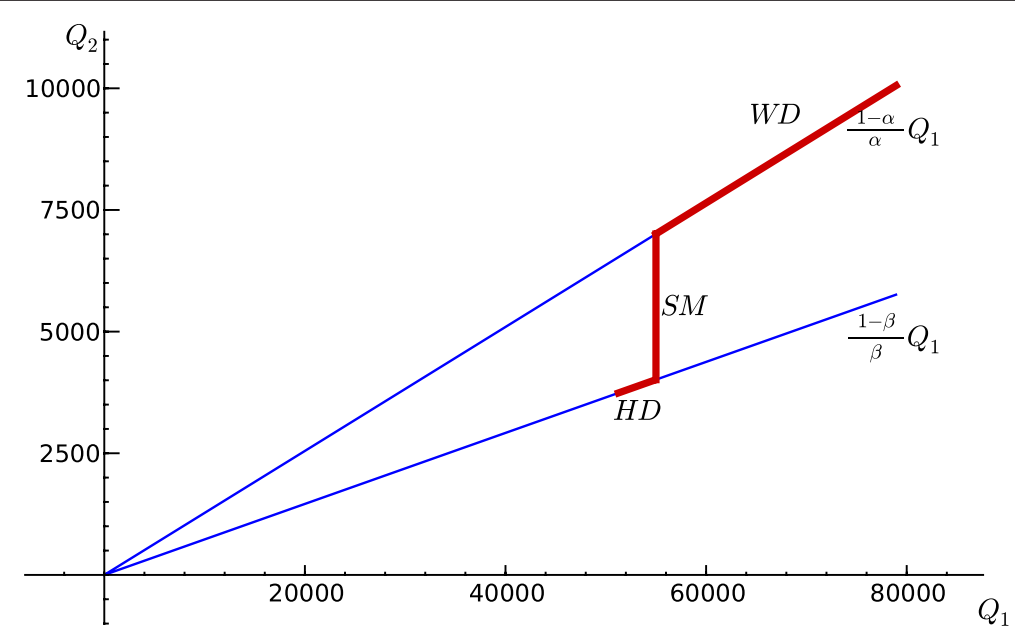

Figure 1 The kinky nature of demand for public goods when $\boldsymbol{\beta}>\boldsymbol{\alpha}$. As $w^{f}$ increases, demand moves along the thick line. (Here $w^{m}=55.000, \alpha=0.887, \beta=0.932$ and $w=0.191$ ). 


$$
Q_{2}=\left\{\begin{array}{ccc}
\frac{(1-\beta) w^{m}}{P_{2}} & \text { if } & w^{f} \leq \frac{\omega}{1-\omega} w^{m} \\
\frac{(1-\beta)(1-\omega)\left(w^{f}+w^{m}\right)}{P_{2}} & \text { if } & w^{f} \in\left[w^{m} \frac{\omega}{1-\omega}, w^{m} \frac{1-\beta(1-\omega)}{\beta(1-\omega)}\right] \\
\frac{(1-\omega) w^{f}-\omega w^{m}}{P_{2}} & \text { if } w^{f} \in\left[w^{m} \frac{1-\beta(1-\omega)}{\beta(1-\omega)}, w^{m} \frac{1-\alpha(1-\omega)}{\alpha(1-\omega)}\right] \\
\frac{(1-\alpha)(1-\omega)\left(w^{f}+w^{m}\right)}{P_{2}} & \text { if } & w^{f}>w^{m} \frac{1-\alpha(1-\omega)}{\alpha(1-\omega)} .
\end{array}\right.
$$

Situation 2: $\beta<\alpha$

$$
\begin{aligned}
& l^{f}=\left\{\begin{array}{cl}
1 & \text { if } w^{f} \leq \frac{\omega}{1-\omega} w^{m} \\
\omega\left(1+\frac{w^{m}}{w^{f}}\right) & \text { if } w^{f}>\frac{\omega}{1-\omega} w^{m}
\end{array}\right. \\
& Q_{1}=\left\{\begin{array}{ccc}
\frac{\beta w^{m}}{P_{1}} & \text { if } & w^{f} \leq \frac{\omega}{1-\omega} w^{m} \\
\frac{\beta(1-\omega)\left(w^{f}+w^{m}\right)}{P_{1}} & \text { if } & w^{f} \in\left[w^{m} \frac{\omega}{1-\omega}, w^{m} \frac{1-(1-\beta)(1-\omega)}{(1-\beta)(1-\omega)}\right] \\
\frac{(1-\omega) w^{f}-\omega w^{m}}{P_{1}} & \text { if } w^{f} \in\left[w^{m} \frac{1-(1-\beta)(1-\omega)}{(1-\beta)(1-\omega)}, w^{m} \frac{1-(1-\alpha)(1-\omega)}{(1-\alpha)(1-\omega)}\right] \\
\frac{\alpha(1-\omega)\left(w^{f}+w^{m}\right)}{P_{1}} & \text { if } & w^{f}>w^{m} \frac{1-(1-\alpha)(1-\omega)}{(1-\alpha)(1-\omega)}
\end{array}\right. \\
& Q_{2}=\left\{\begin{array}{ccc}
\frac{(1-\beta) w^{m}}{P_{2}} & \text { if } & w^{f} \leq \frac{\omega}{1-\omega} w^{m} \\
\frac{(1-\beta)(1-\omega)\left(w^{f}+w^{m}\right)}{P_{2}} & \text { if } & w^{f} \in\left[w^{m} \frac{\omega}{1-\omega}, w^{m} \frac{1-(1-\beta)(1-\omega)}{(1-\beta)(1-\omega)}\right] \\
\frac{w^{m}}{P_{2}} & \text { if } w^{f} \in\left[w^{m} \frac{1-(1-\beta)(1-\omega)}{(1-\beta)(1-\omega)}, w^{m} \frac{1-(1-\alpha)(1-\omega)}{(1-\alpha)(1-\omega)}\right] \\
\frac{(1-\alpha)(1-\omega)\left(w^{f}+w^{m}\right)}{P_{2}} & \text { if } & w^{f}>w^{m} \frac{1-(1-\alpha)(1-\omega)}{(1-\alpha)(1-\omega)} .
\end{array}\right.
\end{aligned}
$$

In both cases, the result is more specific than in Proposition 2. For a low ratio $w^{f} / w^{m}$, the husband is the dictator (HD), and for a high ratio $w^{f} / w^{m}$, the wife is the dictator (WD). In this special case, however, we have an unambiguous ordering and two thresholds, such that we have HD below the lower threshold, WD above the upper threshold, and split might (SM) for all wage ratios between the two thresholds. As a final remark, note that when the husband is the dictator, then the wife can or cannot participate to the labor market. This will depend on the (potential) wage ratio: for a relatively low wage ratio, she will not work, while she will work if the wage ratio is higher than some threshold (see equation 7). In the split might regime, she will always work. The same applies to the case where she is the dictator.

\subsection{Estimation strategy}

As is clear from above, the household demand system for female leisure and both public goods has a kinked nature. Figure 1 highlights this. Moreover, the kinks are determined endogenously since they depend on the spouses' preference parameters and relative wage rates. We will specify an econometric model accounting for the endogenous kinks that can be estimated with maximum likelihood. This model is similar to traditional econometric models with unobserved and endogenous regimes such as Goldfeld and Quandt (1975).

Obviously, female labor supply choices and the allocation of resources to children can be expected to depend on the number of children and their age structure. To account for this observed heterogeneity across the households in the data, we let the preference 
parameters $\alpha, \beta$ and $\omega$ depend on a series of variables that capture the age structure of the children in the household ${ }^{7}$. We use dummy variables capturing the following categories: (1) all the children in the household are less than 6 years old; (2) the oldest child is between 6 and 11, and there is at least one child less than 6; (3) all children are between 6 and 11; (4) the oldest child is between 12 and 17, and at least one child is less than 12; (5) all children are between 12 and 17; and (6) the oldest child is older than 17, and at least one child is younger than 17 . The reference category is the category for which all the children are younger than 6 . The other five categories are associated with the respective dummy variables $c_{1}, \ldots, c_{5}$. Moreover, to impose that the parameters $\alpha, \beta$ and $\omega$ are always between 0 and 1 so that the Cobb-Douglas utility functions are well-behaved, we specify them through the following functions:

$$
\begin{aligned}
& \alpha=\exp \left(\alpha_{0}+\alpha_{1} c_{1}+\ldots+\alpha_{5} c_{5}\right) /\left(1+\exp \left(\alpha_{0}+\alpha_{1} c_{1}+\ldots+\alpha_{5} c_{5}\right)\right) \\
& \beta=\exp \left(\beta_{0}+\beta_{1} c_{1}+\ldots+\beta_{5} c_{5}\right) /\left(1+\exp \left(\beta_{0}+\beta_{1} c_{1}+\ldots+\beta_{5} c_{5}\right)\right) \\
& \omega=\exp \left(\omega_{0}+\omega_{1} c_{1}+\ldots+\omega_{5} c_{5}\right) /\left(1+\exp \left(\omega_{0}+\omega_{1} c_{1}+\ldots+\omega_{5} c_{5}\right)\right) .
\end{aligned}
$$

It is easily seen that in each (sub)regime within the situations (14) and (15), adding up is satisfied: the sum of expenditures on the two composite public goods and female leisure always equals the household's full budget (i.e., $w^{f} l^{f}+\mathbf{P}^{\prime} \mathbf{Q}=w^{f}+w^{m}$ ). This implies that, as in standard demand analysis, one of the goods in the three-good demand system may be left out. We chose to model the household's demand for both public goods, so that the wife's leisure is omitted.

To estimate the model, we need to be explicit about the error terms. Optimization errors in the demand equations are introduced, translating into good-specific additive error terms. We assume that these errors are uncorrelated across households but potentially correlated across goods within a given household. Let $Q_{i 1}$ and $Q_{i 2}$ denote couple is demand for the composite non-children's public good and the child related public good respectively, and let $\mathbf{x}_{i}=\left(w_{i}^{f}, w_{i}^{m}, P_{i 1}, P_{i 2}, n c, a^{f}\right)^{\prime}$ denote the vector of exogenous variables in our model. Observed demands are assumed to be equal to $f_{1}^{r, s}\left(\mathbf{x}_{i}\right)+\epsilon_{i 1}$ and $f_{2}^{r, s}\left(\mathbf{x}_{i}\right)+\epsilon_{i 2}$, where $f_{k}^{r, 1}$ (for goods $k=1,2$ and regions $\left.r=1,2,3,4\right)$ correspond to the lefthand sides of equations (14) and $f_{k}^{r, 2}$ to those in (15). We assume that the vector of error terms is independent of $\mathbf{x}$ and is drawn from the following bivariate normal distribution:

$$
\left(\begin{array}{c}
\epsilon_{i 1} \\
\epsilon_{i 2}
\end{array}\right) \sim N_{2}\left[\left(\begin{array}{l}
0 \\
0
\end{array}\right),\left(\begin{array}{cc}
\sigma_{\epsilon_{1}}^{2} & \rho \sigma_{\epsilon_{1}} \sigma_{\epsilon_{2}} \\
\rho \sigma_{\epsilon_{1}} \sigma_{\epsilon_{2}} & \sigma_{\epsilon_{2}}^{2}
\end{array}\right)\right],
$$

where the standard deviations $\sigma_{\epsilon_{k}}(k=1,2)$ and the correlation between $\epsilon_{i 1}$ and $\epsilon_{i 2}$, denoted by $\rho$, need to be estimated.

This completes the specification of the model. Since we have completely specified the distribution of the error terms given the regressors, the model can be estimated with maximum likelihood. To derive expressions for the likelihood contributions of all households, we introduce two times four couple-specific dummy variables $d_{i}^{r, 1}$ and $d_{i}^{r, 2}(r=1, \ldots, 4)$ that indicate the (sub)regime in which a couple operates, on the basis of the preference parameters of both spouses and their wage rates. The first four dummy variables $d_{i}^{r, 1}$ $(r=1, \ldots, 4)$ refer to the situation where $\beta_{i}>\alpha_{i}$ (the wife values the child related public good more than the husband), while the other four dummy variables $d_{i}^{r, 2}(r=1, \ldots, 4)$ refer to the alternative situation where $\beta_{i}<\alpha_{i}$. In each situation, the four dummy variables indicate the (sub)regime in which a couple operates. Recall that the regime in which 
the husband is a dictator is associated with two subregimes: one where the wife is not working and another one where the wife is working. Depending on the situation and the (sub)regime, household specific demand equations apply; see equations (14) and (15). Given the above assumptions, the likelihood contribution of couple $i$ is equal to:

$$
\begin{aligned}
g_{i}\left(Q_{i 1}, Q_{i 2} \mid \mathbf{x}_{i}\right)= & \sum_{r=1}^{4} d_{i}^{r, 1}\left\{\frac { 1 } { 2 \pi \sigma _ { \epsilon _ { 1 } } \sigma _ { \epsilon _ { 2 } } \sqrt { 1 - \rho ^ { 2 } } } \operatorname { e x p } \left[-\frac{1}{2\left(1-\rho^{2}\right)}\left(\frac{Q_{i 1}-f_{1}^{r, 1}\left(\mathbf{x}_{i}\right)}{\sigma_{\epsilon_{1}}}\right)^{2}\right.\right. \\
& \left.\left.+\left(\frac{Q_{i 2}-f_{2}^{r, 1}\left(\mathbf{x}_{i}\right)}{\sigma_{\epsilon_{2}}}\right)^{2}-2 \rho \frac{Q_{i 1}-f_{1}^{r, 1}\left(\mathbf{x}_{i}\right)}{\sigma_{\epsilon_{1}}} \frac{Q_{i 2}-f_{2}^{r, 1}\left(\mathbf{x}_{i}\right)}{\sigma_{\epsilon_{2}}}\right]\right\} \\
& +\sum_{r=1}^{4} d_{i}^{r, 2}\left\{\frac { 1 } { 2 \pi \sigma _ { \epsilon _ { 1 } } \sigma _ { \epsilon _ { 2 } } \sqrt { 1 - \rho ^ { 2 } } } \operatorname { e x p } \left[-\frac{1}{2\left(1-\rho^{2}\right)}\left(\frac{Q_{i 1}-f_{1}^{r, 2}\left(\mathbf{x}_{i}\right)}{\sigma_{\epsilon_{1}}}\right)^{2}\right.\right. \\
& \left.\left.+\left(\frac{Q_{i 2}-f_{2}^{r, 2}\left(\mathbf{x}_{i}\right)}{\sigma_{\epsilon_{2}}}\right)^{2}-2 \rho \frac{Q_{i 1}-f_{1}^{r, 2}\left(\mathbf{x}_{i}\right)}{\sigma_{\epsilon_{1}}} \frac{Q_{i 2}-f_{2}^{r, 2}\left(\mathbf{x}_{i}\right)}{\sigma_{\epsilon_{2}}}\right]\right\} .
\end{aligned}
$$

Combining all $n$ households, we obtain the following sample loglikelihood function:

$$
\ln L=\sum_{i=1}^{n} \ln g_{i}\left(Q_{i 1}, Q_{i 2} \mid \mathbf{x}_{i}\right) .
$$

Maximizing this loglikelihood function leads to the estimates $\widehat{\alpha}_{j}, \widehat{\beta}_{j}, \widehat{\omega}_{j}(j=0,1,2), \widehat{\sigma}_{\epsilon_{k}}$ $(k=1,2)$ and $\widehat{\rho}$. On the basis of these estimates, each spouse's relative preferences for the child related public good vis-a-vis the composite non-children good and (for women) for leisure can be estimated, as well as the (sub)regime in which each couple operates.

\section{Data}

For the empirical analysis in this paper we have used the Consumer Expenditure Survey (CEX) collected by the Bureau of Labor Statistics of the U.S. Department of Labor. Like most authors in the consumption literature that use the CEX (e.g., Deaton and Paxson 1994; Attanasio and Weber 1995; and Attanasio and Davis 1996) we have compiled a data set from the quarterly Interview Survey (IS) that collects data through a recall questionnaire rather than from the biweekly Diary Survey (DS) that collects data through a daily purchase questionnaire ${ }^{8}$. This was done for three reasons. First, the IS contains more observations. Second, the IS was especially designed to collect data on major expenditure items. The most substantial elements of child expenditures, such as tuition fees, classify as such. Third, the expenditure component directly related to children is larger - both in terms of absolute and relative value - in the IS than in the DS.

The CEX data set contains household observations from 1998 until 2007. The IS has a rotating panel setup in which a household is interviewed at maximum four times in one year. We aggregate all family expenditures to the annual level so that we can link the consumption information to the (yearly) income information. In the event that a family was observed only two or three times within one year, we multiplied observed consumption with the appropriate factor. The waves we use contain 104,049 unique household observations in total.

We construct a sample that is best suited for our structural approach. It includes observations of all married couples with one, two or three children (of which at least one of these is less than 17 years old), with spouses aged between 25 and 60, in which the 
husband works at least 25 hours a week for at least 40 weeks a year, and in which neither of the spouses is enrolled in college or university nor is self-employed. Families with one or both spouses currently attending college or university are excluded because we want to be sure that tuition expenditures can be classified as expenditures for the children. Deleting households with underemployed or unemployed men greatly simplifies the empirical model and the estimation procedure, whereas it leads to a loss of only seven percent of observations. Households that included other adults were also dropped. To make the direct expenditures on children comparable on an absolute level, we differentiate between the subsamples of families with one, two and three children. Finally, to get rid of outliers, we dropped all households where the wage of one of the spouses or the expenditures on children is below the 1st or above the 99th percentile. Because of all these constraints we impose on the selection of the estimation sample, our sample is considerably smaller than the complete CEX sample: it contains 7,757 observations.

For the estimation of the structural model parameters we need four variables: $l^{f}$, the wife's leisure; $Q_{2}$, which contains an estimate of total yearly child expenditures per household; $w^{m}$, the husband's wage rate; and $w^{f}$, which is the wife's wage rate. Not all child expenditures are separately observed in the CEX. As we do not know who consumes what, it is unclear whether expenditures such as sweets or cinema tickets were intended for children or for adults. For some categories it can however be ruled out that the goods were intended for adults. These expenditure categories include school meals, infant furniture, boys apparel, girls apparel, boys and girls footwear, infants apparel, toys, educational books and supplies, and elementary school, high school and college tuition and fees. We aggregate four quarterly expenditure data points to obtain an estimate of household expenditures at the annual level.

Price information is also obtained from the Bureau of Labor Statistics. Seasonally adjusted Urban Consumer Price Indices that were reported per calendar month have been used. As we need a separate price index for children's goods, we use a U.S. city average by expenditure category and commodity and service group. This means that we do not take regional price variation into account. We compute a monthly CPI for child expenditures by averaging the available separate product CPIs and taking account of the weights that these products have in the total expenditures on children goods. Separate CPIs were available for all components of $Q_{2}$, except for baby furniture and school meals. As the quarterly IS interviews take place throughout all months of the year, our data set contains 120 monthly values of $Q_{2}$ 's CPI. Because households report expenditures over the previous three months, we assign the CPI that pertains to the third month prior to the interview to the expenditures in a certain quarter. We take the average of these CPI's to obtain an annual price observation. Cumulative inflation on our basket of child related goods has been 32.0 percent from January 1998 until January 2008, which amounts to a yearly average inflation rate of 2.8 percent.

The CEX documents total yearly household net income as well as individuals' gross labor incomes. We have employed two alternative ways to estimate the husband's net labor income. If the household received no non-labor income we derived it as the percentage of household's net income corresponding to his gross labor income share. If the household did receive some non-labor income, we computed his net wage on the basis of his gross wage using an estimated spline relation between gross and net income in the households that did not receive any non-labor income. 
Potential female wage income is based on the same gross to net conversion as male wage income. Moreover, the hourly wage rate is computed for all employed women but imputed for all women that are unemployed or out of the labor force at the time of the survey. To do the imputations, we estimated a Heckman selection model in which the exclusion restriction is the number of children a women has - this affects selection into paid employment but has no effect on the wage rate. The Heckman model controls for the wife's education level, age group, her state of residence, and for the year of the survey. It is estimated using the total CEX data set, not only our estimation sample. The potential female wage income is then computed by multiplying the (imputed) wage rate with the average weekly number of hours worked by men times 52 (the number of weeks). The female wage rate was imputed in $18.5 \%, 22.8 \%$ and $29.4 \%$ of the households in our samples with one child, two children, and three children, respectively (the percentages of mothers that did not participate in the labor market).

Table 1 displays summary statistics for the three subsamples. As expected, mean and median expenditures on child related goods increase with the number of children. The mean and median hourly wage rates are much higher for the husbands than for the wives in our sample, and do not vary substantially with the number of children. For both wage rates and for expenditures, the mean exceeds the median, in line with the usual finding that these variables are right-skewed.

\section{Estimation results}

Let us now focus on the estimation results for couples with one, two and three children. Preference parameter estimates were obtained by means of the estimation strategy outlined above. They are shown in Table 2. It is clear from the results that preferences over child's expenditures and the other expenditures of husbands and wives differ from each other. This difference is reflected in most parameters and is most obvious for the parameters associated with the age composition of the children, which in almost all cases are statistically significant and have a different sign for husbands $(\beta)$ and wives $(\alpha)$. This implies that spouses' marginal propensities to spend on children and other goods move in different directions if the family composition moves away from the benchmark (all children younger than 6). We also ran a formal test of the joint null hypothesis that $\alpha_{i}=\beta_{i}$ for $i=0, \ldots, 5$. The hypothesis that spouses have the same marginal propensities to spend on children's goods and other consumption is strongly rejected ( $p$-value 0.000). Taken together, this is strong evidence, both in statistical terms as well as in economic terms, against the unitary model.

Table 1 Summary statistics (Estimation sample; 7,858 observations)

\begin{tabular}{llll}
\hline & One child & Two children & Three children \\
\hline Number of households & 2716 & 3713 & 1328 \\
Mean child expenditures & $\$ 3896$ & $\$ 4303$ & $\$ 4281$ \\
Median child expenditures & $\$ 2257$ & $\$ 2790$ & $\$ 2880$ \\
Mean hourly wage husband & $\$ 23.42$ & $\$ 24.66$ & $\$ 24.30$ \\
Median hourly wage husband & $\$ 19.57$ & $\$ 20.77$ & $\$ 20.06$ \\
Mean hourly wage wife & $\$ 16.39$ & $\$ 16.41$ & $\$ 15.12$ \\
Median hourly wage wife & $\$ 14.27$ & $\$ 13.91$ & $\$ 12.51$ \\
Wife in labor force & $81.52 \%$ & $77.16 \%$ & $70.63 \%$ \\
\hline
\end{tabular}


Table 2 Estimation results for couples

\begin{tabular}{llc}
\hline Parameter & Estimate & St. error \\
\hline$\alpha_{0}$ & 4.445 & 0.288 \\
$\alpha_{1}$ & -1.560 & 0.293 \\
$\alpha_{2}$ & -1.199 & 0.295 \\
$\alpha_{3}$ & -1.219 & 0.293 \\
$\alpha_{4}$ & -1.077 & 0.294 \\
$\alpha_{5}$ & -0.663 & 0.145 \\
$\beta_{0}$ & 3.147 & 0.123 \\
$\beta_{1}$ & 0.316 & 0.165 \\
$\beta_{2}$ & 0.678 & 0.166 \\
$\beta_{3}$ & 0.362 & 0.149 \\
$\beta_{4}$ & 0.238 & 0.140 \\
$\beta_{5}$ & -0.054 & 0.128 \\
$\omega_{0}$ & -1.254 & 0.030 \\
$\omega_{1}$ & 0.001 & 0.046 \\
$\omega_{2}$ & -0.114 & 0.042 \\
$\omega_{3}$ & -0.090 & 0.056 \\
$\omega_{4}$ & -0.270 & 0.045 \\
$\omega_{5}$ & -0.089 & 0.060 \\
$\sigma_{\epsilon_{1}}$ & 0.146 & 0.003 \\
$\sigma_{\epsilon_{2}}$ & 0.044 & 0.001 \\
$\rho$ & -0.129 & 0.015 \\
\hline Note: $\boldsymbol{\alpha}_{1}-\boldsymbol{\alpha}_{5} \boldsymbol{\beta}_{1}-\boldsymbol{\beta}_{5}$ and $\boldsymbol{\omega}_{1}-\omega_{5}$ are the coefficients of the dummies for household composition see Section 3.2.
\end{tabular}

The estimation results imply that spouses' preferences with respect to the allocation of the household's expenditures differ from each other. Let us now have a look at the implication of this on the couples' location in the different regimes discussed in Section 2. On the basis of the estimated preference parameters in Table 2, the expected numbers of couples in each of the (sub)regimes can be calculated; they depend on the estimated values of $\beta$ vis-à-vis that of $\alpha$ (see equations (14) and (15)), as well as on the wage ratios. The obtained number of households per (sub)regime and the associated proportions are presented in Table 3.

A first conclusion that can be drawn from the results in Table 3 is that in the majority of the households, the husband values the child's expenditures less than the wife (i.e., $\widehat{\beta}>\widehat{\alpha}$ in about $52 \%$ of the couples). Secondly, the table demonstrates that the husband is a dictator in the majority of the couples in our sample (more precisely, about 54\%). This implies that the spending pattern of these households is according to the husband's preferences. Recall from Section 3 that a husband dictatorship can be associated with

Table 3 Proportion of couples in the different regimes

\begin{tabular}{lll}
\hline$\widehat{\boldsymbol{\beta}}>\widehat{\boldsymbol{\alpha}}$ & & \\
\hline Husband dictator & 473 households & $6.10 \%$ \\
Split might & 64 households & $0.83 \%$ \\
Wife dictator & 3506 households & $45.20 \%$ \\
\hline$\widehat{\beta} \leq \widehat{\alpha}$ & & \\
\hline Husband dictator & 3714 households & $47.88 \%$ \\
Split might & 0 households & $0 \%$ \\
Wife dictator & 0 households & $0 \%$ \\
\hline
\end{tabular}


both a spouse who does not participate in the labor market and a working spouse. This feature is also reflected in our results: in about $14 \%$ of the husband dictatorships, the female does not work, while in the remaining couples the female works. In a sizeable set of the couples (about $45 \%$ ), the wife is a dictator who determines the spending pattern. A split might regime applies to almost $1 \%$ of the households; in all of these households the husband values the child's expenditures less than the wife. Note that in wife dictatorships and the split might regime, females are working as demonstrated in Section 3.

These results are in line with the message of Browning et al. (2010), who showed that regimes are endogenous rather than that they reflect specialization inside the household, which is driven by traditional gender roles as in Lundberg and Pollak (1993). Finally, it is interesting to observe that a dictatorship regime (that is not gender-specific) occurs in most households. Recall that the type of a given household in general depends on both spouses' preferences, their relative wages and the prices of the private and public goods. Specific to our empirical model is that all household resources are spent on publicly consumed goods. Moreover, the empirical results demonstrated that both spouses derive utility from the consumption of these public goods. Given this, having a partner who acts as a dictator is not necessarily very harmful for one's utility (though, of course, utility would be higher if she/he was the dictator herself/himself). It is an open empirical question whether similar results would be obtained for very different commodity bundles in which there is more room for divergent spouses' preferences. We leave this question for future research.

\section{Conclusion}

In this paper, we model the consumption and labor supply behavior of a couple in a non-cooperative setting by adopting a Nash approach. Using minimal assumptions, we prove that demand for public goods is defined by only three regimes. Either demand for public goods is solely determined by the preferences of one of the partners (Husband Dictatorship or Wife Dictatorship), or by the preferences of both spouses, who take into account each other's contributions to public goods (Split Might). The particular regime that applies to a couple is shown to depend on the spouses' relative wage rates. This resembles the endogenous regimes that depend on exogenous individual incomes in Browning et al. (2010).

By imposing more structure on the general model, we can derive testable implications on observed demand for public goods and labor supply that allow testing the model against the standard unitary model where a couple behaves as a single decision maker. The model is then applied to a sample of couples drawn from the Consumer Expenditure Survey (CEX) whereby we focus on expenditures on children's goods as a public good. We find that the standard unitary model is rejected in favor of our non-cooperative model, in the sense that spouses' preferences with respect to the allocation of the household resources differ. Using the estimated preference parameters, we can divide households into dictatorship and split might regimes. It turns out that the spending pattern reflects the husband's preferences in about $54 \%$ of the couples in our sample. Still, in about $45 \%$ of the households, the wife acts as a dictator. Only a small fraction (about 1\%) of the couples is characterized by a split might regime. It seems rather striking that there is either a male or a female dictator in about $99 \%$ of the couples. Part of the explanation can be found in the fact that we assume that the household members only spend money on public goods 
that are appreciated by both spouses. Under this assumption, it is not necessarily too harmful for one' utility to have a partner who acts as a dictator.

\section{Endnotes}

${ }^{1}$ See Lundberg and Pollak (1993) and Chen and Woolley (2001) for examples. In the cooperative models of Manser and Brown (1980) and McElroy and Horney (1981), the alternative threat point of divorce is used.

${ }^{2}$ It goes without saying that all theoretical results apply to same-sex couples as well. For notational reasons we stick to the traditional husband and wife terminology.

${ }^{3}$ Our analysis does not substantially change if individual non-labor incomes are also considered. The definition of the different regimes becomes more complicated though as it depends on the sums of both labor and non-labor incomes, where the former are endogenous (given that labor supply is driven by the wage rate, the individual non-labor income and the prices of the private and public goods).

${ }^{4}$ Allowing for such corner solutions adds inequalities to the optimality conditions. This complicates notation without adding insight. On the other hand, the corner solutions for individual contributions to public goods are essential in the current context since they characterize the nature of the equilibrium outcomes, as we show below.

${ }^{5} w=0$ would also imply that someone does not participate.

${ }^{6}$ It follows from Theorem 1.2 in Fudenberg and Tirole (1991, p. 34) that a pure strategy Nash equilibrium exists in our case. Multiple equilibria cannot be ruled out.

${ }^{7}$ Note that the number of children is assumed to be exogenously given, as is rather standard in this type of empirical analyses. See Becker (1960) for an early economic theory on fertility decisions.

${ }^{8}$ For a detailed comparison of the Interview Survey and the Diary Survey see Battistin (2004).

\section{Appendix: Proofs of results}

\section{Proof of Lemma 1}

We define

$$
\begin{aligned}
d l & =\varepsilon \\
d q_{k} & =-\frac{w}{p_{k}} \varepsilon \\
u(\varepsilon) & =u\left(l+d l, \mathbf{q}+d q_{k} \iota_{k}, \mathbf{Q}\right)
\end{aligned}
$$

where $\iota_{k}$ denotes a vector which equals 1 (one) at position $k$ and is zero everywhere else. Note that $d l$ and $d q_{k}$ are defined in such a way that $\varepsilon \neq 0$ is feasible in terms of the budget restriction.

It follows that

$$
u^{\prime}(\varepsilon)=u_{l}-u_{q_{k}} \frac{w}{p_{k}} .
$$

First, consider the case where $w>0$. Then we prove by contradiction that the equality in the lemma holds. Note that $\frac{u_{l}}{u_{q_{k}}}>\frac{w}{p_{k}}$ implies that utility increases with $\varepsilon$ contradicting equation (2). We need to be careful though as $\varepsilon>0$ is not possible with $l=1$. However at $l=1$ we have $q_{k}=0$ (as there is no income to spend on private goods) and thus $u_{q_{k}}=+\infty$ (by assumption 3). Since $u_{l}$ is finite at $l=1$ (by assumption 3), we cannot have $\frac{u_{l}}{u_{q_{k}}}>\frac{w}{p_{k}}$. Similarly, note that $\frac{u_{l}}{u_{q_{k}}}<\frac{w}{p_{k}}$ implies $\varepsilon<0$ would raise utility again, contradicting equation (2). It is not possible to have $\varepsilon<0$ at $l=0$. But due to assumption 3, we cannot have $\frac{u_{l}}{u_{q_{k}}}<\frac{w}{p_{k}}$ at $l=0$. 
Second, consider $w=0$. Then we have $l=1, q_{k}=0$. Due to assumptions 1 and 3 , we then have

$$
\frac{u_{l}}{u_{q_{k}}}=0=\frac{w}{p_{k}}
$$

and the equality in the lemma holds.

\section{Proof of proposition 1}

The proposition implies that we need to rule out two cases. First, we need to rule out that $u_{Q_{k}}^{j}>\lambda^{j} \mathbf{P}_{k}$ for any partner $j \in\{f, m\}$ and any public good $Q_{k}$. Second, we need to rule out that $u_{\mathbf{Q}}=\lambda \mathbf{P}$ for both partners.

Suppose (by contradiction) that $u_{Q_{k}}^{j}>\lambda^{j} \mathbf{P}_{k}$. If $w^{m}>0$, assumption 1 implies that the husband will contribute to every public good if the wife does not contribute to that public good. Similarly, if $w^{f}>0$, the wife will contribute to each public good if the husband does not. In either case we have $Q_{k}>0$ for each public good $k$, and hence $u_{Q_{k}}^{j}$ is finite for both partners. Given the Nash assumption that $Q_{k}^{(-j) *}$ is given, partner $j$ can raise utility by increasing $Q_{k}^{j}$ which contradicts equation (2).

Second, assume (by contradiction) that $u_{\mathbf{Q}}=\lambda \mathbf{P}$ for both partners. This would imply

$$
\frac{u_{Q_{k}}^{f}}{u_{Q_{k^{\prime}}}^{f}}=\frac{P_{k}}{P_{k^{\prime}}}=\frac{u_{Q_{k}}^{m}}{u_{Q_{k^{\prime}}}^{m}}
$$

for each pair of public goods $Q_{k}, Q_{k^{\prime}}$. However, this contradicts assumption 5.

\section{Proof of proposition 2}

Consider $w^{m}>0$ and $w^{f}=0$. Hence $\mathbf{Q}^{f}=0$ as the wife earns no income. Given assumption 3 it is optimal for the husband to contribute to each public good $Q_{k}$. Hence $u_{Q_{k}}^{f}$ is finite for each public good $Q_{k}$. Since $w^{f}=0$ implies that $\mathbf{q}^{f}=0$, we have $\lambda^{f}=+\infty$ so $u_{\mathbf{Q}^{f}}^{f}<\lambda^{f} \mathbf{P}$. Moreover, the first order conditions for utility maximization of the husband implied by the Nash equilibrium with $\mathbf{Q}^{f}=0$ imply $u_{\mathbf{Q}^{m}}^{m}=\lambda^{m} \mathbf{P}$. Hence, indeed we are in regime HD. By continuity this also holds for $w^{f}>0$ close enough to zero.

The proof of the existence of $\rho_{1}$ is similar but then starting from $w^{f}>0, w^{m}=0$. This gives us regime WD. By continuity we are also in regime WD for $w^{m}>0$ close enough to zero.

\section{Competing interests}

The IZA Journal of Labor Economics is committed to the IZA Guiding Principles of Research Integrity. The authors declare that they have observed these principles.

\section{Acknowledgements}

We would like to thank Editor Pierre Cahuc, an anonymous referee, Geoffrey Dunbar, Arie Kapteyn, Tobias Klein and Elena Stancanelli, as well as seminar participants at Tilburg University, the ESPE-2012 conference in Bern and the workshop "Advances in Family Economics and Applications to Developing Countries" in Paris for useful comments and suggestions. Jan Boone gratefully acknowledges financial support from The Netherlands Organisation for Scientific Research (NWO) through a $\mathrm{VICl}$ grant.

Frederic Vermeulen gratefully acknowledges financial support from the Research Fund KU Leuven through the grant STRT/12/001 and from the FWO through the grant G057314N.

Responsible editor: Pierre Cahuc

\section{Author details}

${ }^{1}$ CEPR and IZA, CentER, Tilec, Tilburg University, P.O. Box 90153, NL-5000 LE Tilburg, The Netherlands. ${ }^{2}$ IZA, CPB Netherlands Bureau for Economic Policy Analysis, P.O. Box 80510, NL-2508 GM The Hague, The Netherlands. ${ }^{3}$ Netspar and IZA, CentER, Tilburg University, P.O. Box 90153, NL-5000 LE Tilburg, The Netherlands. ${ }^{4}$ IZA, Department of Economics, University of Leuven, Naamsestraat 69, B-3000 Leuven, Belgium. 
Received: 14 July 2014 Accepted: 11 September 2014

\section{Published: 10 Nov 2014}

\section{References}

Apps P, Rees R (1988) Taxation and the household. J Public Econ 35:355-369

Ashworth J, Ulph D (1981) Household models in C Brown (ed.) Taxation and Labour Supply, London, George Allen \& Unwin, $117-133$

Attanasio O, Davis S (1996) Relative wage movements and the distribution of consumption. J Political Econ 104:1227-1262

Attanasio O, Weber G (1995) Is consumption growth consistent with intertemporal optimization? Evidence from the consumer expenditure survey. J Political Econ 103(6):1121-1157

Battistin E (2004) Errors in survey reports of consumption expenditures. IFS, London

Becker G (1960) An economic analysis of fertility, in Universities-National Bureau (ed.), Demographic and Economic

Change in Developed Countries. Princeton University Press, Princeton, 209-240

Becker G (1973) A theory of marriage: Part I. J Political Econ 81:813-846

Becker G (1974) A theory of social interactions. J Political Econ 82:1063-1093

Becker G (1981) A Treatise on the Family. Harvard University Press, Cambridge MA

Bergstrom T, Blume L, Varian H (1986) On the private provision of public goods. J Public Econ 29:25-49

Blundell R, Chiappori P-A, Meghir C (2005) Collective labor supply with children. J Political Econ 113:1277-1306

Browning M (2000) The saving behaviour of a two-person household. Scand J Econ 102:235-251

Browning M, Chiappori P-A (1998) Efficient intra-household allocations: a general characterization and empirical tests. Econometrica 66:1241-1278

Browning M, Chiappori P-A, Lechene V (2010) Distributional effects in household models: separate spheres and income pooling. Econ J 120:786-799

Chen Z, Woolley F (2001) A Cournot-Nash model of family decision making. Econ J 111:722-748

Cherchye L, Vermeulen F (2008) Nonparametric analysis of household labor supply: goodness of fit and power of the unitary and the collective model. Rev Econ Stat 90:267-274

Cherchye L, De Rock B, Vermeulen F (2009) Opening the black box of intra-household decision-making: Theory and non-parametric empirical tests of general collective models. J Political Econ 117:1074-1104

Cherchye L, Demuynck T, De Rock B (2011) Revealed preference analysis of non-cooperative household consumption. Econ J 121:1073-1096

Cherchye L, De Rock B, Vermeulen F (2012) Married with children. A collective labor supply model with detailed time use and intrahousehold expenditure information. Am Econ Rev 102:3377-3405

Chiappori P-A (1988) Rational household labor supply. Econometrica 56:63-89

Chiappori P-A (1992) Collective labor supply and welfare. J Political Econ 100:437-467

d'Aspremont C, Dos Santos Ferreira R (2014) Household behavior and individual autonomy: an extended Lindahl mechanism. Econ Theory 55:643-664

Deaton A, Paxson C (1994) Intertemporal choice and inequality. J Political Econ 102:437-467

Duflo E (2003) Grandmothers and granddaughters: old-age pensions and intrahousehold allocation in South Africa. World Bank Econ Rev 17:1-25

Fudenberg D, Tirole J (1991) Game Theory. MIT Press, Cambridge MA

Goldfeld S, Quandt R (1975) Estimation in a disequilibrium model with the value of information. J Econometrics 3:325-348

Lechene V, Preston I (2011) Noncooperative household demand. J Econ Theory 146:504-527

Leuthold J (1968) An empirical study of formula income transfers and the work decision of the poor. J Hum Resour 3:312-323

Lundberg S, Pollak R (1993) Separate spheres bargaining and the marriage market. J Political Econ 101:988-1010

Lundberg S, Pollak R, Wales T (1997) Do husbands and wives pool their resources? Evidence from the United Kingdom child benefit. J Human Resour 2:463-480

Manser M, Brown M (1980) Marriage and household decision-making: a bargaining analysis. Int Econ Rev 21:31-44

McElroy M, Horney M (1981) Nash-bargained household decisions: toward a generalization of the theory of demand. Int Econ Rev 22:333-349

Samuelson P (1956) Social indifference curves. Q J Econ 70:1-22

Thomas D, Contreras D, Frankenberg E (1997) Child health and the distribution of household resources at marriage. Working paper, RAND Corporation, Santa Monica

\subsection{6/2193-8997-3-11}

Cite this article as: Boone et al:: Kinky choices, dictators and split might: a non-cooperative model for household consumption and labor supply. IZA Journal of Labor Economics 2014, 3:11 